Supplement of Biogeosciences, 14, 3525-3547, 2017

https://doi.org/10.5194/bg-14-3525-2017-supplement

(C) Author(s) 2017. This work is distributed under

the Creative Commons Attribution 3.0 License.

(c) (1)

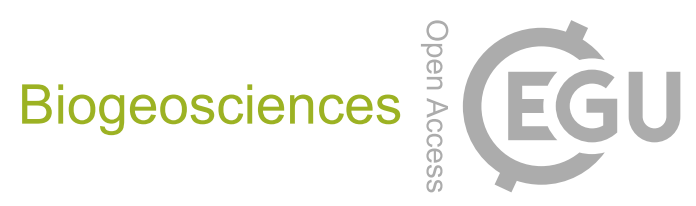

Supplement of

\title{
Leveraging 35 years of Pinus taeda research in the southeastern US to constrain forest carbon cycle predictions: regional data assimilation using ecosystem experiments
}

\author{
R. Quinn Thomas et al. \\ Correspondence to: R. Quinn Thomas (rqthomas@ vt.edu)
}

The copyright of individual parts of the supplement might differ from the CC BY 3.0 License. 


\section{Supplemental Material}

\section{Section 1: Description of 3-PG model}

Our analysis used a modified version of the 3-PG model. For completeness, we describe the entire model and highlight our modifications.

\section{Section 1.1: Canopy photosynthesis}

Monthly carbon assimilation (gross primary productivity; GPP) was based on absorbed photosynthetically active radiation (APAR) and a quantum yield variable $\left(\alpha_{\mathrm{e}}\right)$ described below in Equation 5 (Bryars et al., 2013; Gonzalez-Benecke et al., 2016; Landsberg and Waring, 1997).

$\mathrm{GPP}=\mathrm{APAR} \times \alpha_{\mathrm{e}}$

Equation 1

APAR was a function of the down-welling photosynthetically active radiation (PAR), the leaf area index (LAI), and the canopy closure.

APAR $=$ PAR $\times\left(1-e^{(-k \times L A I)}\right) \times f($ closure $)$

Equation 2

The canopy closure function, $\mathrm{f}($ closure), increased APAR as a stand reached a parameterized age of canopy closure (fullCanAge) (Bryars et al., 2013).

$\mathrm{f}($ closure $)=\min \left(1, \frac{\text { StandAge }}{\text { fullCanAge }}\right)$

Equation 3

StandAge was a variable describing the age of the simulated stand. LAI was a derived variable calculated by dividing the foliage biomass (WF) by a specific leaf area (SLA). Based on (Gonzalez-Benecke et al., 2016), SLA decreased as a stand aged.

SLA $=$ SLA $1+($ SLA0 $-S L A 1) \times \mathrm{e}^{\left(-\ln (2) \times\left(\frac{\text { Standage }}{\text { tSLA }}\right)^{2}\right)}$

Equation 4

\section{Section 1.2: Environmental modifiers of photosynthesis and/or transpiration}

The variable $\alpha_{\mathrm{e}}$ was a function of a maximum quantum yield parameter $(\alpha)$ modified by mean daily air temperature ( $\mathrm{T}_{\text {avg }}$ ), number of frost days (FrostDays), available soil water (ASW), vapor pressure deficit (VPD), atmospheric $\mathrm{CO}_{2}$ concentration, stand age, and soil fertility (FR) where each of the modifiers took a value between 0 and 1 (except for the $\mathrm{CO}_{2}$ modifier which took values greater than 1 if atmospheric $\mathrm{CO}_{2}$ was greater than $350 \mathrm{ppm}$ ).

$\alpha_{\mathrm{e}}=\alpha \times \mathrm{f}\left(\mathrm{T}_{\text {avg }}\right) \times \mathrm{f}\left(\right.$ FrostDays, $\left.\mathrm{T}_{\min }\right) \times \mathrm{f}(\mathrm{VPD}) \times \mathrm{f}(\mathrm{ASW}) \times \mathrm{f}\left(\mathrm{CO}_{2}\right) \times \mathrm{f}($ Age $) \times \mathrm{FR} \quad$ Equation 5

The mean daily temperature modifier, $\mathrm{f}\left(\mathrm{T}_{\mathrm{avg}}\right)$, was based on a parameterized optimum $\left(\mathrm{T}_{\mathrm{opt}}\right)$, maximum $\left(\mathrm{T}_{\max }\right)$, and minimum ( $\left.\mathrm{T}_{\min }\right)$ temperature of photosynthesis using: 
$f\left(T_{\text {avg }}\right)=\frac{\left(T_{\text {avg }}-T_{\min }\right)}{\left(T_{\text {avg }}-T_{\min }\right)} \times \frac{\left(T_{\text {max }}-T_{\text {avg }}\right)}{\left(T_{\max }-T_{\text {opt }}\right)} \frac{\left(T_{\text {max }}-T_{\text {opt }}\right)}{\left(T_{\text {opt }} T_{\text {min }}\right)}$

Equation 6

The frost day modifier, $\mathrm{f}$ (FrostDays, $\mathrm{T}_{\mathrm{min}}^{\mathrm{met}}$ ), decreased carbon assimilation proportional to the number of days during the month with minimum temperature below $-1{ }^{\circ} \mathrm{C}$ (FrostDays) (Bryars et al., 2013).

$\mathrm{f}\left(\right.$ frostday, $\left.\mathrm{T}_{\min }\right)=1-\left[\left(1-\mathrm{e}^{\mathrm{kF} * \mathrm{~T}_{\text {min }}^{\mathrm{met}}}\right) \times \frac{\text { FrostDays }}{30}\right]$

Equation 7

The magnitude of the decrease was an exponential function of the mean daily minimum temperature over the month, $\mathrm{T}_{\text {min }}^{\text {met }}$ (Gonzalez-Benecke et al., 2016). The vapor pressure deficit modifier, $\mathrm{f}(\mathrm{VPD})$, was an exponential function where the modifier decreased as mean daily VPD increased (Gonzalez-Benecke et al., 2016).

$f(V P D)=e^{- \text {CoeffCond } \times V P D}$

Equation 8

The soil moisture modifier, $\mathrm{f}(\mathrm{ASW})$, was a logistic function of the ASW relative to a specified maximum available soil water (MaxASW) (Landsberg and Waring, 1997).

$\mathrm{f}($ ASW $)=\frac{1}{1+\left[\frac{(1-\text { moist_ratio })}{\text { SWconst }}\right]^{\text {SWpower }}}$

Equation 9

where

moist_ratio $=\frac{\text { ASW }}{\text { MaxASW }}$

Equation 10

In this version, the two parameters governing the soil moisture modifier function were the same across all soil types. Therefore, MaxASW was the key difference between sites. The soil texture dependent parameters used in prior applications of 3-PG were removed to simplify the number of parameters in the model and could be reintroduced and optimized in future applications.

The atmospheric $\mathrm{CO}_{2}$ modifier, $\mathrm{f}\left(\mathrm{CO}_{2}\right)$, was a saturating function of atmospheric $\mathrm{CO}_{2}$, where the modifier was set to one at $350 \mathrm{ppm}$ (Almeida et al., 2009). The atmospheric $\mathrm{CO}_{2}$ modifier was able to have values greater than one when atmospheric $\mathrm{CO}_{2}$ was greater than $350 \mathrm{ppm}$.

$\mathrm{f}\left(\mathrm{CO}_{2}\right)=\frac{\text { fCalpha }_{\mathrm{x}} \times \mathrm{CO}_{2}}{350 \times\left(\mathrm{fCalpha}_{\mathrm{x}}-1\right)+\mathrm{CO}_{2}}$

Equation 11

where

fCalpha $_{\mathrm{x}}=\frac{\text { fCalpha700 }}{\left(2-\mathrm{fCalpha700)}^{-}\right.}$

Equation 12

The age modifier, $\mathrm{f}($ Age), decreased canopy quantum yield as a stand aged (Bryars et al., 2013). 
$\mathrm{f}($ Age $)=\frac{1}{1+\left[\frac{\text { RelAge }}{\text { rAge }}\right]^{\text {nAge }}}$

Equation 13

where

RelAge $=\frac{\text { StandAge }}{\text { MaxAge }}$

Equation 14

MaxAge did not represent the maximum possible age of a stand, rather it was a parameter controlling the shape of Equation 13. It is possible for MaxAge and nAge to be parameterized so that the age modifier was effectively one for all ages (i.e., no decline in quantum yield as a stand ages). Therefore, the calibrated value of MaxAge could be older than the age of a typical harvest rotation

\section{Section 1.3: Soil fertility}

The soil fertility modifier, FR, was a proxy for the nutrient availability. In prior applications of the 3-PG model, FR was a site-specific value between zero and one (Bryars et al., 2013; Landsberg and Waring, 1997) that modified the quantum use efficiency and the allocation to total roots (prior applications of 3-PG combined fine and coarse roots). To simplify parameters and assumptions in the 3-PG model for application to data assimilation, we modified 3-PG so that FR only modified quantum use efficiency. Therefore, for a given LAI and climatic conditions, a lower FR represented a reduced capacity to convert light captured by LAI to photosynthate. In turn, lower photosynthesis at the site with lower FR will lead to lower LAI. An FR of one indicated that the site was not limited by nutrient availability. FR values less than one represented the degree of nutrient limitation at the site.

FR could be estimated for a site or from biophysical covariates. In the former, FR is directly estimated for a site, which effectively represents a fixed effect in a statistical model. However, fixing FR for each site used in optimization does not allow for predictions at sites that were not used in calibration because FR at a new site would be unknown. Alternatively, FR could be a function of site characteristics that allow for spatial predictions of FR based on maps of the characteristics. We used a hybrid of these two approaches.

First, we used site index (SI; the mean height of dominant or co-dominant trees for a specified base age: 25 years, in this study) and mean annual temperature (MAT) to predict FR at sites that did not receive nutrient additions. Site index has previously been used to predict FR using a saturating or logistic function (Gonzalez-Benecke et al., 2016; 2014b; Subedi et al., 2015). Site index is a useful metric of stand productivity because it is commonly measured or modeled (Sabatia and Burkhart, 2014) and integrates many environmental factors that influence growth. When comparing sites with similar climate and available soil water, site index represents differences in nutrient bioavailability. Since site index integrates multiple environmental factors beyond nutrient bioavailability, including factors that are already represented in the prediction of photosynthesis (climate, available soil water, etc.), the influence of these other environmental factors should be factored out of the relationship between site index and FR. This helps avoids covariance between FR parameterization and the parameterization of other environmental modifiers and avoids double counting the influence of the other environmental factors on 
photosynthesis. We used the long-term MAT for the site to represent the environmental factors that are already accounted for in the photosynthesis calculating and modified the saturating function of the site SI in (Gonzalez-Benecke et al., 2014b; 2016) to include a temperature modifier,

$\mathrm{FR}=\frac{1}{1+\mathrm{e}^{\mathrm{FR} 1 \times \mathrm{MAT}-\mathrm{FR} 2 \times \mathrm{SI}}}$

Equation 15

Equation 15 assumed that the same SI should correspond to a lower FR in stands at the warmer extent of the species range (i.e., Southern Georgia) than stands in the cooler extent (i.e., Virginia) (Figure 1a). FR1 and FR2 are the parameters governing the shape of the relationship. The MAT used in Equation 15 was based on the 35-year mean annual temperature of site (1979-2011; (Abatzoglou, 2013)) and did not vary during a simulation. By not varying during a simulation and averaging over a 35-year period, MAT represented a long-term climatic driver of soil fertility rather than an inter- and intra-annual driver of fertility.

Second, we directly estimated FR for sites that received nutrient additions at rates that did not allow for the assumption of FR $=1$ (i.e., nutrients were only added once). For these nutrient addition sites, we treated FR as an estimated site-specific parameter that must be equal to or greater than the FR predicted by equation 15 for the corresponding control plot. A previous application of the 3-PG model to the loblolly pine ecosystem used a parameter to control the sensitivity of quantum yield to FR, parameter FNo(Bryars et al., 2013). Here, we set $\mathrm{FN}_{0}$ equal to zero to prevent covariation and identifiability issues with the FR parameters in Equation 15.

\section{Section 1.4: Allocation}

A fixed fraction (y) of GPP (equation 1) was available for growth as net primary production (NPP), which assumed a time and space invariant NPP to GPP ratio (Bryars et al., 2013; Gonzalez-Benecke et al., 2016).

$\mathrm{NPP}=\mathrm{GPP} \times \mathrm{y}$

Equation 16

NPP was allocated to leaf biomass ( $\mathrm{pF})$, stem (bole + branches) biomass (pWS), coarse root biomass (pWCR), and fine root biomass (pFR). The pattern of NPP allocation to plant tissues varied as the average size of the average tree increased. Specifically, the ratio of NPP allocated to leaf biomass versus stem biomass ( $\mathrm{pFS}$ ) asymptotically decreased as the average diameter of a tree at the site increased (Bryars et al., 2013).

$\mathrm{pFS}=\left(\right.$ pfsConst $\times$ avDBH $\left.{ }^{\mathrm{pfsPower}}\right) \times \mathrm{fCpFS}$

Equation 17

where pfsPower and pfsConst were functions of foliage to stem allocation at $2 \mathrm{~cm}(\mathrm{pFS} 20)$ and $20 \mathrm{~cm}$ diameter $(\mathrm{pFS} 2)$

pfsPower $=\frac{\log \left(\frac{\mathrm{pFS} 20}{\mathrm{pFS} 2}\right)}{\log \left(\frac{20}{2}\right)}$

Equation 18 
$\mathrm{pfsCont}=\frac{\mathrm{pFS} 2}{2^{\mathrm{pspower}}}$

Equation 19

The average diameter of a tree (avDBH) used in the allocation calculation was based on an allometric relationship between biomass of the average tree (AvStemMass) and diameter (Gonzalez-Benecke et al., 2014a).

$\operatorname{avDBH}=\left(\frac{\text { AvStemMass }}{\text { stemConst }}\right)^{\frac{1}{\text { stemPower }}}$

Equation 20

AvStemMass assumed that all trees had equal stem biomass (WS) by dividing WS by the number of stems $\left(\mathrm{ha}^{-1}\right)$ in the stand (StemNumber)

AvStemMass $=\frac{\text { WS }}{\text { StemNumber }}$

Equation 21

In our version of 3-PG, the ratio of leaf to stem biomass also decreased with atmospheric $\mathrm{CO}_{2}$ based on the following

$\mathrm{fCpFS}=\frac{\mathrm{fCpFS}_{\mathrm{x}} \times \mathrm{CO}_{2}}{350 \times\left(2 \mathrm{fCFS}_{\mathrm{x}}-1\right)+\mathrm{CO}_{2}}$

Equation 22

where

$\mathrm{fCpFS}_{\mathrm{x}}=\frac{\mathrm{fCpFS700}}{(2-\mathrm{fCpFS700)}}$

Equation 23

In our modified version, we separated coarse roots and fine roots. Coarse root biomass was parameterized as a constant fraction of stem biomass allocation (pCRS) and fine root biomass was parameterized as constant proportion of foliage allocation (pRF). Due to the limited availability of fine root biomass data, we removed the dependence of total root allocation (fine and coarse roots) on nutrient, soil water, and vapor pressure deficit that was used in previous versions of the 3-PG (Bryars et al., 2013; Gonzalez-Benecke et al., 2016).

\section{SI Section 1.5: Tissue turnover and mortality}

We introduced a two-cohort model to simulate the turnover of leaf biomass (variable:

leaf_turnover). The life span of loblolly pine needles has been shown to be approximately two years (Albaugh et al., 2010; Sampson et al., 2003). The turnover of leaf biomass was assumed to occur in November and to represent $100 \%$ of the second-year cohort biomass. Allocation to leaf biomass was always to a first-year cohort. Cohort 1 transferred to cohort 2 at the end of the calendar year. Therefore, the three parameters associated with leaf turnover used in previous versions of the 3-PG model were removed from our version. In contrast to leaf dynamics, fine roots were a single cohort and the turnover was a constant proportion throughout the year (root_turnover). 
The turnover of stem and coarse roots was based on a density-dependent mortality rate and constant density-independent mortality rate. The density-dependent mortality rate used a selfthinning law to decrease the number of stems as the average size of a tree increases. Following (Landsberg and Waring, 1997), the stem count (StemNumber) was reduced (stem_turnover_depend) if the average individual tree stem biomass (AvStemMass) was above the thinning curve (the relationship between average stem biomass and total stems per hectare) . The thinning curve was parameterized by the maximum average stem mass using the $\mathrm{WS}_{\mathrm{x} 1000}$ and ThinPower parameters

$\mathrm{WS}_{\max }=\mathrm{WS}_{\mathrm{x} 1000} \times$ AvStemMass ${ }^{\text {ThinPower }}$

Equation 25

Details of how the self-thinning processes was solved can be found in Landsberg and Waring (1997). The stem biomass turnover that was associated with the density-dependent mortality was calculated by assuming that trees that died from thinning were smaller (ms) than the average sized tree in the stand

ws_turnover_depend $=\mathrm{ms} \times \frac{\mathrm{WS}}{\text { StemNumber }} \times$ stem_turnover_depend $\quad$ Equation 26

where ms was the parameter governing the proportion of an averaged size tree that died during self-thinning. Similarly, coarse roots (WCR) died through the same self-thinning process.

wcr_turnover_depend $=\mathrm{ms} \times \frac{\mathrm{WCR}}{\text { StemNumber }} \times$ stem_turnover_depend

Equation 27

In our modified version, we added a density-independent mortality rate that was a constant fraction (mort_rate) of stems and coarse roots

Ws_turnover_independ $=\mathrm{WS} \times$ mort_rate Equation 28

wcr_turnover_independ $=$ WCR $\times$ mort_rate

Equation 29

No foliage or fine roots were removed when a tree died through either mortality processes because their turnover was already accounted for in the leaf life span calculation and the fine root turnover parameter. Therefore, the parameters $\mathrm{mF}$ and $\mathrm{mR}$ used in previous applications of the 3PG model were not used.

\section{SI Section 1.6: Water balance}

Evapotranspiration (ET) was the sum of canopy transpiration and evaporated fraction of rain intercepted by the canopy. The calculation of canopy transpiration used a Penman-Monteith approach that depended on canopy conductance (Conductance), boundary layer conductance (BLcond), vapor pressure deficit, and net radiation (Landsberg and Waring, 1997). Transpiration was further modified by the number of frost days according to the frost day function, 
$\mathrm{f}$ (FrostDays), described in Equation 7. Conductance increased to a maximum canopy conductance (MaxCond) as LAI increased to a value equal or greater than the LAI of maximum conductance (LAIgcx). Conductance was influenced by VPD, ASW, and stand age using the same modifiers as used in the photosynthesis calculation (Equation 5).

Conductance=MaxCond $\times \min \left[1,\left(\frac{\text { LAI }}{\text { LAI }_{\text {gcx }}}\right)\right] \times f g(C O 2) \times f($ VPD $) \times f(A S W) \times f($ Age $)$

Equation 30

The $\mathrm{CO}_{2}$ modifier, $\mathrm{fg}\left(\mathrm{CO}_{2}\right)$ allowed for Conductance to decline as atmospheric $\mathrm{CO}_{2}$ increased based on a parameterized reduction in canopy conductance between 350 and $700 \mathrm{ppm}$ atmospheric $\mathrm{CO} 2$ concentration ( $\mathrm{fCg} 700)$

$\mathrm{fg}\left(\mathrm{CO}_{2}\right)=\frac{\mathrm{fCg}_{0}}{1+\left(\mathrm{fCg}_{0}-1\right) \times\left(\frac{\mathrm{CO}_{2}}{350}\right)}$

Equation 31

where

$\mathrm{fCg}_{0}=\frac{\mathrm{fCg} 700}{(2 \times \mathrm{fCpFS} 700-1)}$

Equation 32

In our application to loblolly pines, we assumed that stomatal conductance did not decrease as atmospheric $\mathrm{CO}_{2}$ levels increased because sap flux measurements at the Duke FACE study found that stomatal conductance on a ground area basis did not change with elevated $\mathrm{CO}_{2}$ (Ward et al., 2013). The maximum conductance parameter (MaxCond) was shared across all sites.

Intercepted rain was assumed to return to the atmosphere through evaporation. Intercepted rain increased with LAI to a maximum (MaxIntcptn) at a parameterized LAI value (LAImaxIntcptn)

Interception $=$ Rain $\times$ MaxIntcptn $\times \min \left(1.0, \frac{\text { LAI }}{\text { LAImaxIntcptn }}\right)$

Equation 33

Runoff occurred when soil water exceeded the specified site-level maximum available soil water after accounting for rain and evapotranspiration during the month.

\section{SI Section 1.7: Understory hardwoods}

To facilitate the most robust integration of eddy-covariance estimates of gross ecosystem productivity (GPP estimated using eddy-covariance measurements) and ET from stands with hardwood species in the understory, we added the capacity to simulate understory hardwoods. The calculation of hardwood photosynthesis parallels the calculation for the overstory pines except that: 1) the PAR available to the understory was the transmitted PAR after pine absorbance, 2) a separate GPP was calculated using the transmitted PAR and an understory specific maximum quantum yield $\left.\left(\alpha \_h\right), 2\right)$ the allocation parameters were specific to the understory (pFS_h, pRF_h and pCRS_h), 4) only density-independent mortality (mort_rate_h) 
was simulated, 5) NPP was added to a bud biomass pool, and 6) spring growth of foliage was from the bud biomass pool (Bud_to_leaf). The temperature, VPD, frost day, soil fertility, and soil water modifiers were equal to those used for the overstory pines. LAI was calculated for the understory hardwoods by dividing the foliage biomass (WFh) by the hardwood specific leaf area (SLAh). Unlike the overstory pines, SLAh was a parameter and did not vary with stand age. The LAI value used in the canopy conductance calculation was the sum of pine and hardwood LAI and the maximum conductance parameter (MaxCond) was assumed to apply to both pine and hardwood trees. Canopy transpiration was assigned to pine and hardwoods based on the proportion of total LAI. The hardwood understory dropped leaves in November and grew leaves in April. Therefore, the simulated photosynthesis and ET during the winter months was solely from the pines in the stand.

\section{SI Section 1.8: Mass balance equations}

Overall, the 3-PG model used in this study simulated the monthly change in eleven state variables per plot: four stocks for pines, five stocks for understory hardwoods, pine stem density (stems ha-1), and available soil water (ASW).

$\begin{array}{lr}\frac{\mathrm{dWF}}{\mathrm{dt}}=\mathrm{NPP} \times \mathrm{pF}-\text { leaf_turnover } & \text { Equation } 34 \\ \frac{\mathrm{dWS}}{\mathrm{dt}}=\mathrm{NPP} \times \mathrm{pS}-\mathrm{ws} \text { tturnover_depend }-\mathrm{ws} \text {-turnover_independ } & \text { Equation } 35 \\ \frac{\mathrm{dWCR}}{\mathrm{dt}}=\mathrm{NPP} \times \mathrm{pCR}-\mathrm{wcr} \text { turnover_depend }-\mathrm{wcr} \text { turnover_independ } & \text { Equation } 36 \\ \frac{\mathrm{dWR}}{\mathrm{dt}}=\mathrm{NPP} \times \mathrm{pR}-\text { root_turnover }-\mathrm{wr} \text { _turnover_depend } & \text { Equation } 37 \\ \frac{\mathrm{dStemNumber}}{\mathrm{dt}}=-\mathrm{StemNumber} \times \text { mort_rate }- \text { stem_turnover_depend } & \text { Equation } 38 \\ \frac{\mathrm{dASW}}{\mathrm{dt}}=\text { rain }+ \text { irrigation }- \text { canopy_transpiration }- \text { interception } & \end{array}$

where irrigation was equal to the amount of rain necessary to prevent negative ASW values (Bryars et al., 2013). The dynamics of the hardwood understory was simulated using the following equations

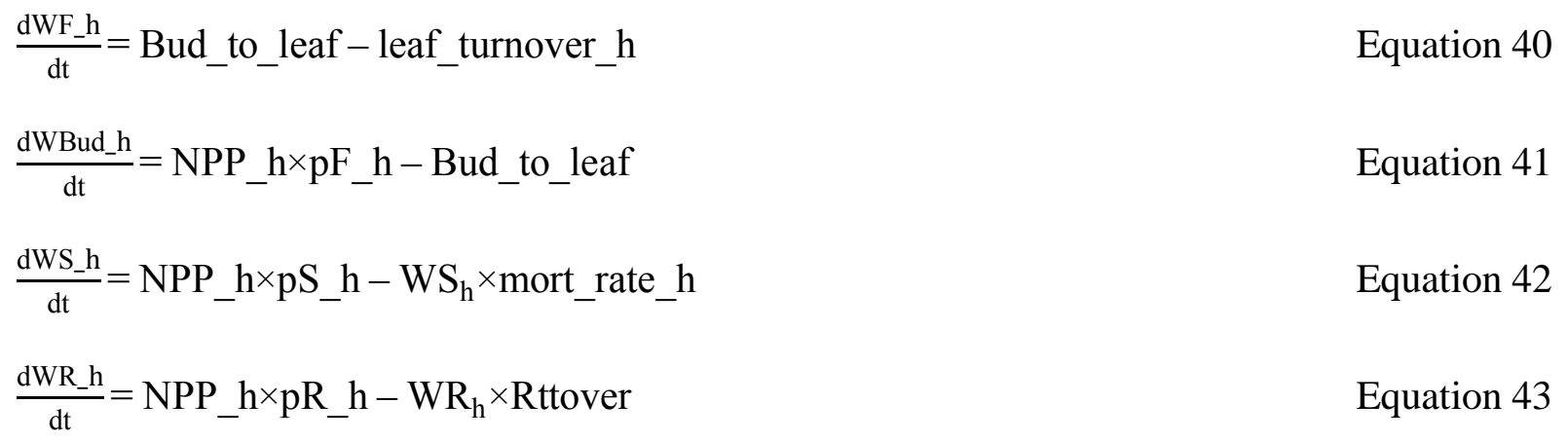


$\frac{\mathrm{dWCR} \_\mathrm{h}}{\mathrm{dt}}=\mathrm{NPP} \times \mathrm{pCR} \_\mathrm{h}-\mathrm{WCR}_{\mathrm{h}} \times$ mort_rate_h

Equation 44 
Table S1. Parameters not estimated using data assimilation, prior distributions, and the sensitivity of total biomass at age 25 to the parameter

\begin{tabular}{|c|c|c|c|c|}
\hline Parameter & Parameter description & Units & Value & Reference \\
\hline BLcond & Canopy boundary layer conductance & $\mathrm{m} \mathrm{s}^{-1}$ & 0.1 & $1,2,3$ \\
\hline $\mathrm{k}$ & $\begin{array}{l}\text { Extinction coefficient for absorption } \\
\text { of PAR by canopy }\end{array}$ & - & 0.56 & $1,2,3$ \\
\hline fullCanAge & Age at full canopy cover & Years & 3 & $1,2,3$ \\
\hline MaxIntcptn & $\begin{array}{l}\text { Maximum proportion of rainfall } \\
\text { intercepted by canopy }\end{array}$ & - & 0.2 & $1,2,3$ \\
\hline LAImaxIntcptn & $\begin{array}{l}\text { LAI for maximum rainfall } \\
\text { interception }\end{array}$ & - & 5 & $1,2,3$ \\
\hline fCg700 & $\begin{array}{l}\text { Proportional decrease in canopy } \\
\text { conductance between } 350 \text { and } 700 \\
\text { ppm CO } 2\end{array}$ & - & 1 & 4 \\
\hline pCRS_h & $\begin{array}{l}\text { Fraction of stem allocation to coarse } \\
\text { roots }\end{array}$ & - & 0.2 & 5 \\
\hline MortRate_h & $\begin{array}{l}\text { Density independent mortality rate } \\
\text { (understory hardwoods) }\end{array}$ & Month $^{-1}$ & 0.0009 & 5 \\
\hline
\end{tabular}

${ }^{1}$ (Bryars et al., 2013); ${ }^{2}$ (Gonzalez-Benecke et al., 2016); ${ }^{3}$ (Subedi et al., 2015)

${ }^{4}$ (Ward et al., 2013); ${ }^{5}$ (McCarthy et al., 2010) 
Table S2. Posterior medians and $99 \%$ credible intervals for the variance parameters associated with each data stream using the Base data assimilation approach.

\begin{tabular}{lll}
\hline Parameter & Base $(99 \%$ C.I. $)$ & Optimized/Prior Range \\
\hline$\gamma_{\text {foliage }}$ & $1.35(1.23-1.48)$ & $<0.01$ \\
$\gamma_{\text {stem }}$ & $0.13(0.001-0.61)$ & $<0.01$ \\
$\rho_{\text {stem }}$ & $0.14(0.13-0.15)$ & $<0.01$ \\
$\gamma_{\text {FineRoots }}$ & $0.85(0.69-1.07)$ & $<0.01$ \\
$\gamma_{\text {CoarseRoots }}$ & $4.02(3.63-4.5)$ & 0.01 \\
$\gamma_{\text {StemDensity }}$ & $142.0(133.2-150.5)$ & 0.02 \\
$\gamma_{\text {LAI }}$ & $0.55(0.52-0.59)$ & $<0.01$ \\
$\gamma_{\text {GEP }}$ & $0.54(0.29-0.82)$ & $<0.01$ \\
$\rho_{\text {GEP }}$ & $0.09(0.01-0.18)$ & $<0.01$ \\
$\gamma_{\text {ET }}$ & $7.71(3.18-14.71)$ & 0.11 \\
$\rho_{\text {ET }}$ & $0.20(0.12-0.29)$ & $<0.01$ \\
$\gamma_{\text {FoliageProd }}$ & $1.09(0.81-1.47)$ & $<0.01$ \\
$\gamma_{\text {FineRootProd }}$ & $0.56(0.43-0.79)$ & $<0.01$ \\
$\gamma_{\text {HardwoodFoliage }}$ & $0.42(0.34-0.53)$ & $<0.01$ \\
$\gamma_{\text {HardwoodStem }}$ & $2.32(1.93-2.89)$ & 0.01 \\
\hline
\end{tabular}


Supplemental Figures
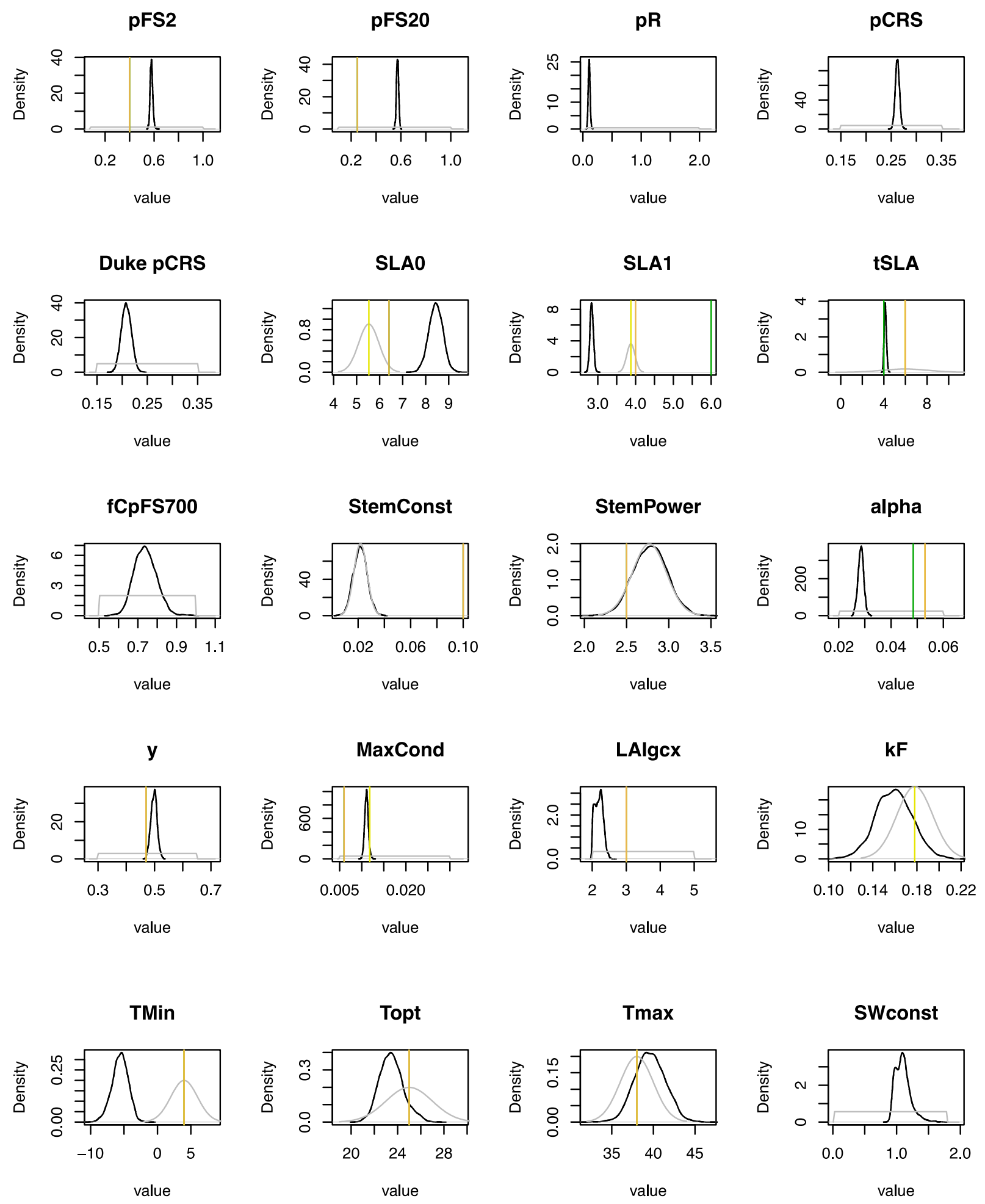


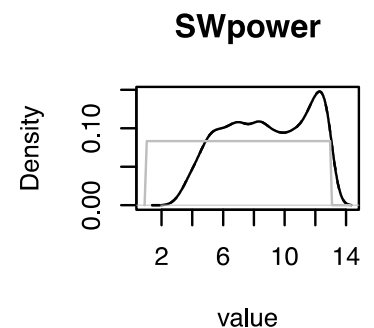

nAge

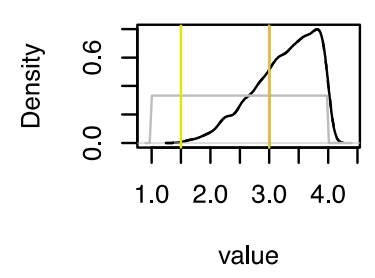

wSx1000
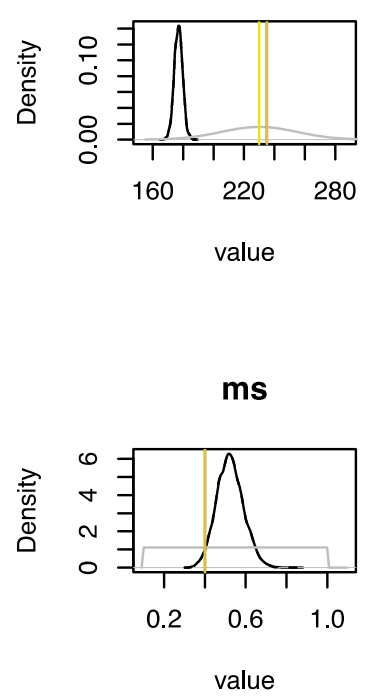

pFS_h

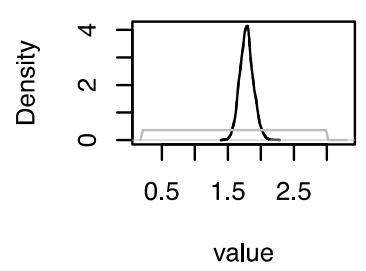

CoeffCond

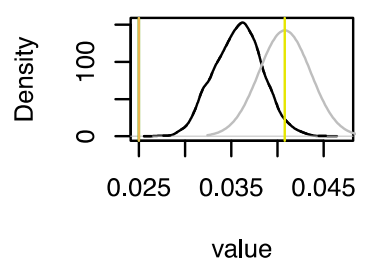

rAge

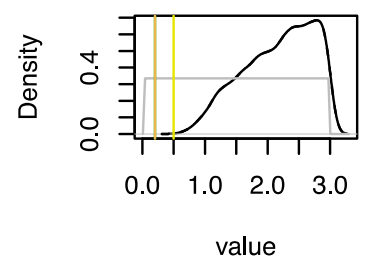

Duke wSx1000

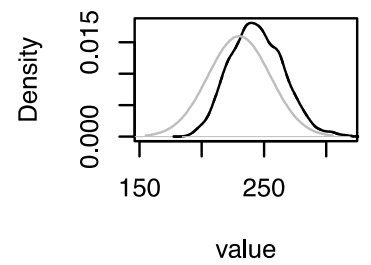

Rttover

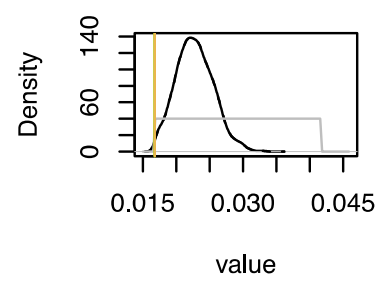

pR_h

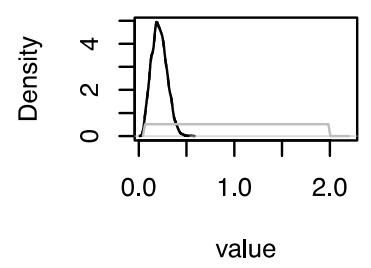

fCalpha700

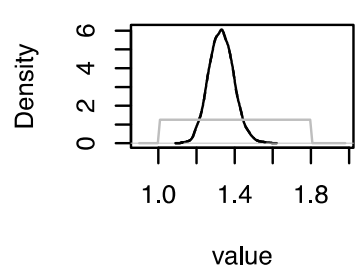

FR1

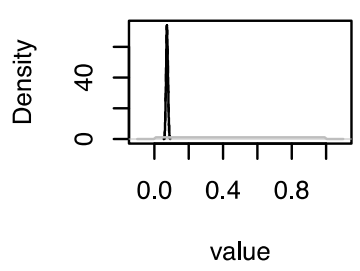

thinPower

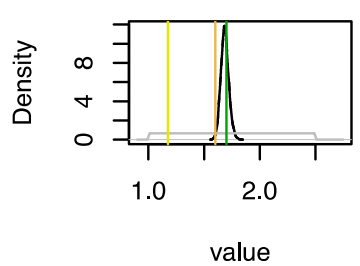

MortRate

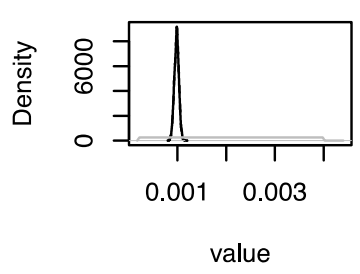

SLA_h

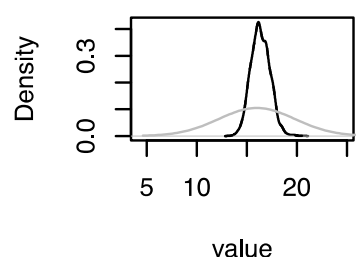

MaxAge

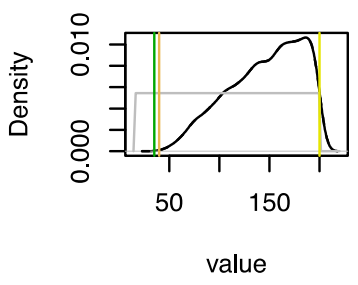

FR2

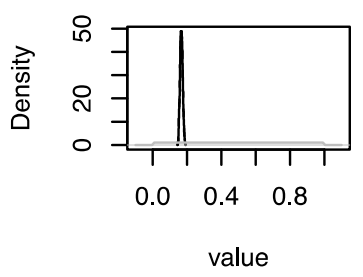

Duke thinPower

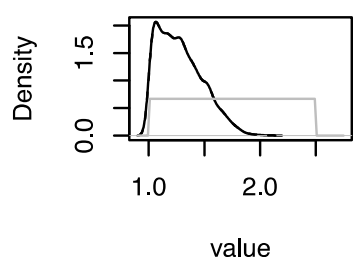

Alpha_h

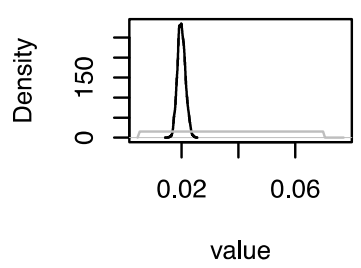

fCalpha700_h

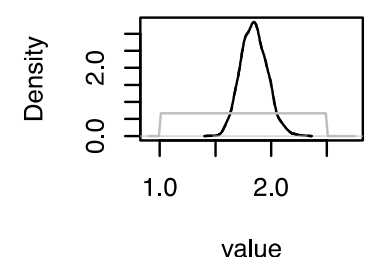



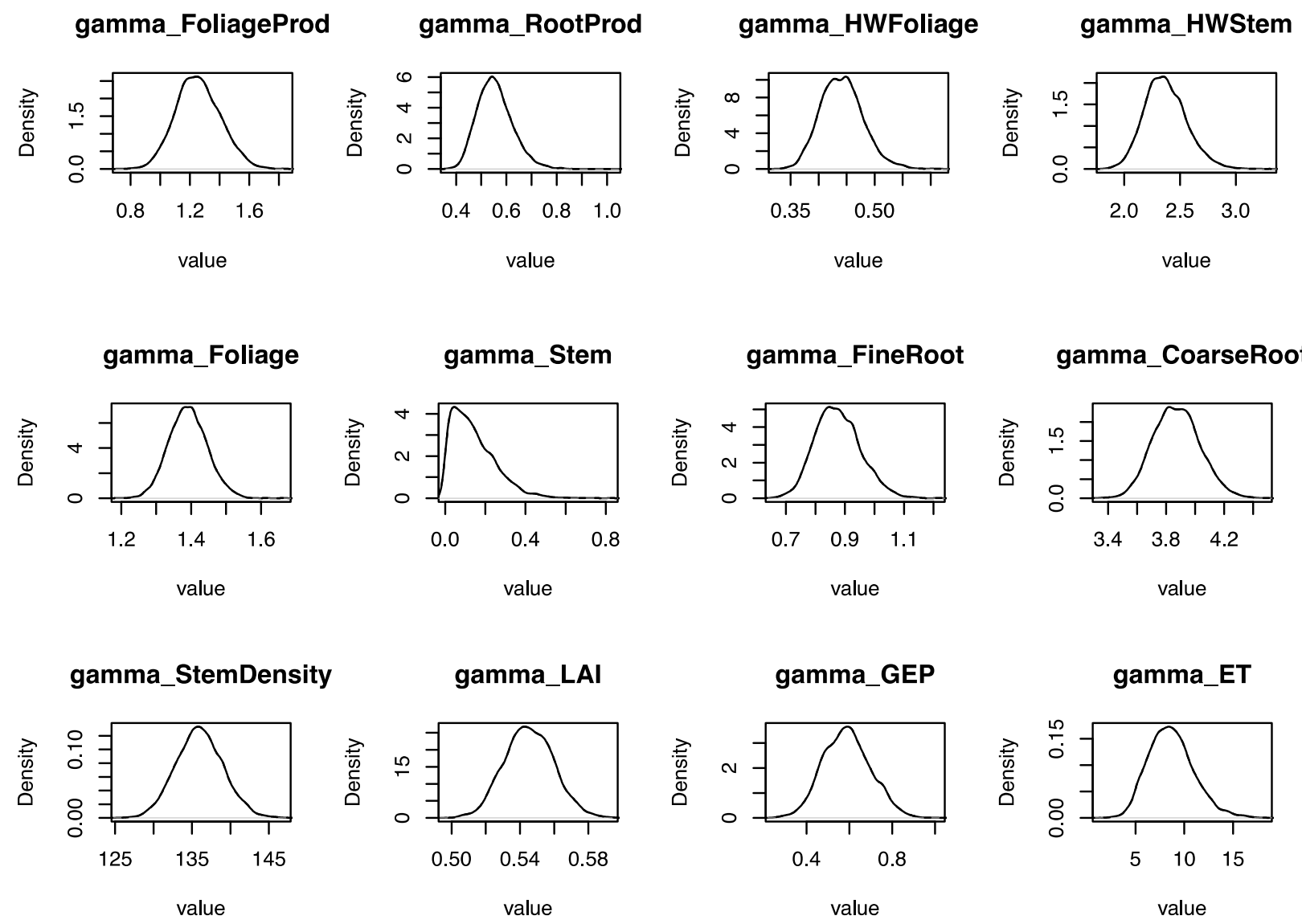

Fig. S1. Prior distributions (grey line), posterior distributions from Base assimilation (black lines) and parameter values used in previous applications of the 3-PG model (yellow: Gonzalez-Benecke et al. (2016), green: Bryars et al. (2013), and tan: Subedi et al. (2015)). 


\section{References}

Abatzoglou, J. T.: Development of gridded surface meteorological data for ecological applications and modelling, International Journal of Climatology, 33(1), 121-131, doi:10.1002/joc.3413, 2013.

Albaugh, T. J., Allen, H. L. and Kress, L. W.: Root and stem partitioning of Pinus taeda, Trees, 20(2), 176-185, doi:10.1007/s00468-005-0024-4, 2005.

Albaugh, T. J., Allen, H. L., Stape, J. L., Fox, T. R., Rubilar, R. A., Carlson, C. A. and Pezzutti, R.: Leaf area duration in natural range and exotic Pinus taeda, Can. J. For. Res., 40(2), 224-234, doi:10.1139/X09-190, 2010.

Almeida, A. C., Sands, P. J., Bruce, J., Siggins, A. W., Leriche, A., Battaglia, M. and Batista, T. R.: Use of a spatial process-based model to quantify forest plantation productivity and water use efficiency under climate change scenarios, pp. 1816-1822, Cairns. 2009.

Bryars, C., Maier, C., Zhao, D., Kane, M., Borders, B., Will, R. and Teskey, R.: Fixed physiological parameters in the 3-PG model produced accurate estimates of loblolly pine growth on sites in different geographic regions, Forest Ecol Manag, 289, 501-514, doi:10.1016/j.foreco.2012.09.031, 2013.

DeLucia, E. H., Drake, J. E., Thomas, R. B. and Gonzalez-Meler, M.: Forest carbon use efficiency: is respiration a constant fraction of gross primary production? Global Change Biology, 13(6), 1157-1167, doi:10.1111/j.1365-2486.2007.01365.x, 2007.

Gonzalez-Benecke, C. A., Gezan, S. A., Albaugh, T. J., Allen, H. L., Burkhart, H. E., Fox, T. R., Jokela, E. J., Maier, C. A., Martin, T. A., Rubilar, R. A. and Samuelson, L. J.: Local and general above-stump biomass functions for loblolly pine and slash pine trees, Forest Ecol Manag, 334, 254-276, doi:10.1016/j.foreco.2014.09.002, 2014a.

Gonzalez-Benecke, C. A., Jokela, E. J., Cropper, W. P., Jr, Bracho, R. and Leduc, D. J.: Parameterization of the 3-PG model for Pinus elliottii stands using alternative methods to estimate fertility rating, biomass partitioning and canopy closure, Forest Ecol Manag, 327(C), 55-75, doi:10.1016/j.foreco.2014.04.030, 2014 b.

Gonzalez-Benecke, C. A., Teskey, R. O., Martin, T. A., Jokela, E. J., Fox, T. R., Kane, M. B. and Noormets, A.: Regional validation and improved parameterization of the 3-PG model for Pinus taeda stands, Forest Ecol Manag, 361, 237-256, doi:10.1016/j.foreco.2015.11.025, 2016.

Landsberg, J. and Waring, R.: A generalised model of forest productivity using simplified concepts of radiation-use efficiency, carbon balance and partitioning, Forest Ecol Manag, 95(3), 209-228, doi:10.1016/S0378-1127(97)00026-1, 1997.

LeBauer, D. S., Dietze, M., Long, S., Mulrooney, P., Rohde, G. S., Wang, D. and Kooper, R.: Biofuel Ecophysiological Traits and Yields Database (BETYdb),, doi:doi:10.13012/J8H41PB9, 2010. 
Matamala, R., Gonzàlez-Meler, M. A., Jastrow, J. D., Norby, R. J. and Schlesinger, W. H.: Impacts of fine root turnover on forest NPP and soil C sequestration potential, Science, 302(5649), 1385-1387, doi:10.1126/science.1089543, 2003.

McCarthy, H. R., Oren, R., Johnsen, K. H., Gallet-Budynek, A., Pritchard, S. G., Cook, C. W., LaDeau, S. L., Jackson, R. B. and Finzi, A. C.: Re-assessment of plant carbon dynamics at the Duke free-air $\mathrm{CO} 2$ enrichment site: interactions of atmospheric [CO2] with nitrogen and water availability over stand development, New Phytol, 185(2), 514-528, doi:10.1111/j.1469-

8137.2009.03078.x, 2010.

Sabatia, C. O. and Burkhart, H. E.: Predicting site index of plantation loblolly pine from biophysical variables, Forest Ecol Manag, 326, 142-156, doi:10.1016/j.foreco.2014.04.019, 2014.

Sampson, D. A., Albaugh, T. J., Johnsen, K. H., Allen, H. L. and Zarnoch, S. J.: Monthly leaf area index estimates from point-in-time measurements and needle phenology for Pinus taeda, Can. J. For. Res., 33(12), 2477-2490, doi:10.1139/x03-166, 2003.

Subedi, S., Fox, T. and Wynne, R.: Determination of fertility rating (FR) in the 3-PG model for loblolly pine plantations in the Southeastern United States based on site index, Forests, 6(9), 3002-3027, doi:10.3390/f6093002, 2015.

Ward, E. J., Oren, R., Bell, D. M., Clark, J. S., McCarthy, H. R., Kim, H.-S. and Domec, J.-C.: The effects of elevated $\mathrm{CO}_{2}$ and nitrogen fertilization on stomatal conductance estimated from 11 years of scaled sap flux measurements at Duke FACE, Tree Physiology, 33(2), 135-151, doi:10.1093/treephys/tps 118, 2013. 